\title{
Permeability of Alkanethiols Self-Assembled Monolayers on Gold Prepared by Neat Thiols and Ethanolic Thiols
}

\author{
Zhiguo Li, Guohua Zhou, Cui Ye, Xuyao Xu, Weizhen Chen, Lingling Zhang*, \\ Chunxia Zheng, and Zhifeng Fu \\ School of Chemistry and Chemical Engineering, Lingnan Normal University, Development Center for \\ New Materials Engineering and Technology in Universities of Guangdong, Zhanjiang, 524048, \\ Guangdong, China \\ *E-mail: marycury@ 163.com
}

doi: $10.20964 / 2016.10 .13$

Received: 30 June 2016 / Accepted: 5 August 2016 / Published: 6 September 2016

In this article we investigated the permeability of alkanethiols $\left(\mathrm{C}_{n} \mathrm{SH}, \mathrm{n}=6,10,12,16\right)$ self-assembled monolayers (SAMs) on gold prepared by neat thiols and ethanolic thiols. The electrochemical parameters (interfacial capacitance $C_{\mathrm{d}}$, phase angle $\Phi_{1 \mathrm{~Hz}}$ and ions transfer resistance $R_{\mathrm{it}}{ }^{*}$ at $1 \mathrm{~Hz}$, current density difference $\Delta j$ and charge transfer resistance $\left.R_{\mathrm{ct}}\right)$ from cyclic voltammetry $(C V)$ and electrochemical impedance spectroscopy $(E I S)$ were used to explore the permeability of SAMs. Results indicated that alkanethiols SAMs prepared by neat thiols had smaller $C_{\mathrm{d}}$ than by ethanolic thiols. Thus, the neat thiols SAMs were more compacted than ethanolic thiols SAMs. The dielectric constant $\varepsilon$ of alkane chain in SAMs were calculated to be 1.2 (neat thiols) and 3.0 (ethanolic thiols) respectively based on the linear slopes of $\mathrm{C}_{\mathrm{d}}^{-1} \sim \mathrm{n}$ plots. A hydrophobic gap possibly existed on neat thiols SAMs-water interface, which might lead to smaller $\varepsilon$ (1.2) than the reported value (2.3) by literatures. The $\Phi_{1 \mathrm{~Hz}}$ of neat thiols SAMs were bigger and close to $88^{\circ}$ as an ions insulator and the ethanolic thiols SAMs were ions permeable SAMs. The permeable constants $(p)$ of neat thiols SAMs and ethanolic thiols SAMs on gold were $0.097 / \mathrm{CH}_{2}$ and $0.111 / \mathrm{CH}_{2}$ respectively based on the linear slopes of $\ln R_{\mathrm{it}}{ }^{*} \sim \mathrm{n}$ plots. However, to our surprise, the tunneling constant $\beta$ of neat thiols SAMs was calculated to be $0.238 / \mathrm{CH}_{2}$ based on the linear slopes of $\ln R_{\mathrm{ct}} \sim \mathrm{n}$ plots $\left(R_{\mathrm{ct}}\right.$ was the charge transfer resistance of $\mathrm{Fe}(\mathrm{CN})_{6}{ }^{3-/ 4-}$ ), which was much smaller than $1.0 / \mathrm{CH}_{2}$ from literatures. We considered that there might be two main reasons: 1) The hydrophobic layer existed on the neat thiols SAMs possibly influenced the $R_{\mathrm{ct}}$ of $\left.\mathrm{Fe}(\mathrm{CN})_{6}{ }^{3-/ 4-} ; 2\right)$ The neat thiols SAMs was not an ideal tunneling system with the collapsed sites possibly existed in SAMs, which might influence the $R_{\mathrm{ct}}$ of $\mathrm{Fe}(\mathrm{CN})_{6}{ }^{3-/ 4-}$. These conclusions provided the important reference for understanding the interfacial characteristics of alkanethiols SAMs on gold in depth.

Keywords: self-assembled monolayers, permeability, neat thiols, ethanolic thiols, gold electrode 


\section{FULL TEXT}

(C) 2016 The Authors. Published by ESG (www.electrochemsci.org). This article is an open access article distributed under the terms and conditions of the Creative Commons Attribution license (http://creativecommons.org/licenses/by/4.0/). 